\title{
COMBINAÇÕES DE SUBSTRATOS E URINA DE VACA NO CRESCIMENTO DE TAMARINDO
}

\author{
COMBINACIONES SUSTRATO Y ORINA DE VACA EN CRECIMIENTO \\ TAMARINDO
}

\section{SUBSTRATE COMBINATIONS AND COW URINE IN GROWTH TAMARINDO}

\author{
Mário Leno Martins VÉRAS ${ }^{1}$ \\ Danila Lima de ARAÚJO² \\ Lunara de Sousa ALVES ${ }^{3}$ \\ Alexandro de Figueiredo ANDRADE ${ }^{4}$ \\ Raimundo ANDRADE ${ }^{5}$
}

RESUMO: A adubação orgânica tem um papel fundamental, além de enriquecer o solo, melhora as características físicas, químicas e biológicas. Objetivou-se com esta pesquisa avaliar combinações de substratos e urina de vaca no crescimento de tamarindo. O estudo foi desenvolvido em ambiente protegido, no setor de viveiricultura da Universidade Estadual da Paraíba no município de Catolé do Rocha/PB. Adotou-se o delineamento experimental inteiramente casualizado (DIC) contendo quatro repetições, no arranjo fatorial 5 x 2, com 10 tratamentos, totalizando 40 plantas experimentais. Estudaram-se cinco combinações de substratos: $\left(\mathrm{C}_{1}=50 \%\right.$ de húmus de minhoca $+50 \%$ de solo; $\mathrm{C}_{2}=50 \%$ de pó de madeira + $50 \%$ de solo; $\mathrm{C}_{3}=$ Areia lavada; $\mathrm{C}_{4}=33 \%$ de pó de madeira $+33 \%$ de húmus de minhoca + $33 \%$ de solo e $\mathrm{C}_{5}=100 \%$ solo) e duas concentrações de urina de vaca: $\left(\mathrm{U}_{1}=1 \%\right.$ e $\left.\mathrm{U}_{2}=5 \%\right)$. Observou-se que o tamarindo respondeu significativamente $(\mathrm{p}<0,01)$ as combinações de substratos. Para as concentrações de urina de vaca todas as variáveis apresentaram efeitos significativos a nível de $(\mathrm{p}<0,01)$ de probabilidade, exceto o peso seco total $(\mathrm{p}<0,05)$. $\mathrm{O}$ tamarindo respondeu bem aos substratos e à urina de vaca.

Palavras-chave: Mudas, adubo, concentrações de fertilizante orgânico.

RESUMEN: La fertilización orgánica tiene un papel fundamental, y enriquecer el suelo, mejora la física, química y biológica. El objetivo de esta investigación fue evaluar sustratos

\footnotetext{
${ }^{1}$ Mestrando em agronomia, Universidade Federal da Paraíba - UFPB/Campus II - Areia - Paraíba - Brasil. mario.deus1992@bol.com.br

${ }^{2}$ Mestre em Engenharia Agrícola, Universidade Federal de Campina Grande - UFCG - Campina Grande Paraíba - Brasil. danilalimaraujo@ hotmail.com

${ }^{3}$ Graduada em Ciências Agrárias, Universidade Estadual da Paraíba - UEPB/Campus IV - CEP 58884-000 -

Catolé do Rocha - Paraíba - Brasil. lunara_alvesuepb@ hotmail.com

${ }^{4}$ Graduado em Ciências Agrárias, Universidade Estadual da Paraíba - UEPB/Campus IV - CEP 58884-000 Catolé do Rocha - Paraíba - Brasil. afigueiredoandrade@bol.com.br

${ }^{5}$ Prof. Doutor do Departamento de Agrárias e Exatas, Universidade Estadual da Paraíba - UEPB/Campus IV CEP 58884-000 - Catolé do Rocha - Paraíba - Brasil. raimundoarndrade@uepb.edu.br
} 
combinaciones y orina de vaca en el crecimiento de tamarindo. El estudio se realizó en un invernadero en el sector viveiricultura de la Universidad del Estado de Paraíba, en el municipio Catolé do Rocha / PB. Hemos adoptado un diseño completamente al azar (DCA) con cuatro repeticiones, en un arreglo factorial 5 x 2, con 10 tratamientos, con un total de 40 plantas experimentales. Estudiamos cinco combinaciones de sustrato: $\left(\mathrm{C}_{1}=50 \%\right.$ humus de lombriz $+50 \%$ de los suelos; $\mathrm{C}_{2}=50 \%$ de madera en polvo $+50 \%$ del suelo; $\mathrm{C}_{3}=$ arena lavada; $\mathrm{C}_{4}$ humus $=33 \%$ de madera en polvo $+33 \%+33 \%$ de las lombrices del suelo y $\mathrm{C}_{5}=$ $100 \%$ de suelo) y dos concentraciones en orina de vaca: (U1 $=1 \%$ y U2 $=5 \%$ ). Se observó que el tamarindo respondió significativamente $(\mathrm{p}<0,01)$ combinaciones de los sustratos. Para la orina de vaca concentraciones de todas las variables afectan significativamente el nivel de $(\mathrm{p}<0,01)$ de la probabilidad, excepto el peso seco total $(\mathrm{p}<0,05)$. Tamarind respondió bien a los sustratos y vaca orina.

Palabras-chave: Plántulas, fertilizantes, abonos orgánicos concentraciones

\begin{abstract}
The organic fertilization has a key role, and enrich the soil, improves the physical, chemical and biological. The objective of this research was to evaluate substrates combinations and cow urine on the growth of tamarind. The study was conducted in a greenhouse in viveiricultura sector of Paraiba State University in municipality Catolé do Rocha/ PB. We adopted a completely randomized design (CRD) with four replications, in a factorial arrangement $5 \times 2$, with 10 treatments, totaling 40 experimental plants. We studied five substrate combinations: $\left(\mathrm{C}_{1}=50 \%\right.$ earthworm humus $+50 \%$ of soil; $\mathrm{C}_{2}=50 \%$ wood powder $+50 \%$ soil; $\mathrm{C}_{3}=$ Washed sand; $\mathrm{C}_{4}=33 \%$ wood powder $+33 \%$ earthworm humus + $33 \%$ of soil and $\mathrm{C}_{5}=100 \%$ soil $)$ and two cow urine concentrations: $\left(\mathrm{U}_{1}=1 \%\right.$ and $\left.\mathrm{U}_{2}=5 \%\right)$. It was observed that tamarind responded significantly $(\mathrm{p}<0,01)$ combinations of the substrates. For cow urine concentrations of all variables affect significantly the level of $(p<0,01)$ of probability, except the total dry weight $(p<0,05)$. Tamarind responded well to the substrates and cow urine.
\end{abstract}

Keywords: Seedlings, fertilizer, organic fertilizer concentrations.

\title{
INTRODUÇÃO
}

A cultura do tamarindo (Tamarindus indica L.) é originária da Índia. No Brasil é cultivado a mais de um século, principalmente no Nordeste, sendo considerada uma árvore de multiuso (FERREIRA, 2008).

Para a implantação de um pomar, deve-se levar em conta o elemento principal, a muda, quando são de qualidade e bem manejadas originam pomares produtivos e de boa rentabilidade, no entanto, para que isto ocorra é essencial o uso de uma boa técnica de formação das mesmas (PASQUAL et al., 2001). 
A agricultura orgânica é um sistema de produção que vem crescendo mundialmente. Pesquisas desenvolvidas apontam um crescimento da agricultura orgânica na América Latina superior a 8,0\% ao ano (WILLER, 2010). A adição de matéria orgânica no solo pode ser feita de várias maneiras, a exemplo da utilização de fertilizantes e matérias orgânicas que influenciam positivamente nos processos biólogicos de decomposição e mineralização da matéria orgânica do solo (PARENTE et al., 2012).

Uma das vantagens na agricultura orgânica é que os fertilizantes podem ser feitos na propriedade, havendo uma economia de dinheiro, visto que o produtor não precisa adquirir outros insumos e os solos apresentam fertilidade diferenciada pela sua qualidade dos fertilizantes orgânicos (TRANI et al., 2013).

O substrato é fundamental para o bom desenvolvimento da plântula e deve ser de boa qualidade para originar mudas de boa qualidade e garantir resultados satisfatórios na produção do pomar (OLIVEIRA et al., 2012). Rodrigues et al., (2012) apontam que para a produção de mudas de boa qualidade deve-se levar em conta alguns pontos: a escolha do substrato bem como a proporção e a combinação de substratos.

Dentre os fertilizantes orgânicos encontrados, a urina de vaca é um elemento natural que substitui os fertilizantes químicos. Apresenta compostos que melhoram a sanidade das plantas, proporcionando mais resistência às fitossanidades, pragas e doenças além de ser rica em potássio e nitrogênio (PESAGRO-RIO, 2001).

Diante do exposto objetivou-se com esta pesquisa avaliar combinações de substratos e urina de vaca no crescimento de tamarindo.

\section{MATERIAIS E MÉTODOS}

O estudo foi desenvolvido em ambiente protegido, no setor de viveiricultura do Centro de Ciências Humanas e Agrárias no Departamento de Agrárias e Exatas da Universidade Estadual da Paraíba no município de Catolé do Rocha/PB, (6²0’38’S; 3744’48”W) e 275 metros de altitude. O clima do município, de acordo com a classificação de Koppen, é do tipo BSW', ou seja, quente e seco do tipo estepe, com temperatura média mensal superior a $18^{\circ} \mathrm{C}$, durante todo o ano.

O delineamento experimental adotado foi inteiramente casualizado (DIC) contendo quatro repetições, no arranjo fatorial $5 \times 2$, com 10 tratamentos, totalizando 40 plantas experimentais. Foram estudados os efeitos de diferentes combinações de substratos $\left(\mathrm{C}_{1}=50 \%\right.$ de húmus de minhoca $+50 \%$ de solo; $\mathrm{C}_{2}=50 \%$ de pó de madeira $+50 \%$ de solo; $\mathrm{C}_{3}=$ Areia 
lavada; $\mathrm{C}_{4}=33 \%$ de Pó de madeira $+33 \%$ de húmus de minhoca $+33 \%$ de solo e $\mathrm{C}_{5}=100 \%$ solo) e das concentrações de urina de vaca aplicadas via solo $\left(\mathrm{U}_{1}=1 \%\right.$ e $\left.\mathrm{U}_{2}=5 \%\right)$.

A água de irrigação foi proveniente de um poço amazonas próximo ao local do experimento e suas características estão presentes na (Tabela 1). A água não apresenta problemas de salinidade, sendo classificada como $\mathrm{C}_{3} \mathrm{~S}_{1}$, podendo ser utilizada para a cultura do tamarindo sem riscos para o crescimento.

Tabela 1. Parâmetros químicos da água de irrigação utilizada na cultura do tamarindo. Catolé do Rocha - PB, UEPB, 2014.

\begin{tabular}{lc}
\hline CARACTERÍSTICAS & VALORES \\
\hline Ph & 8,13 \\
Condutividade Elétrica $\left(\mu \mathrm{S} . \mathrm{Cm}^{-1}\right)$ & 990 \\
Cálcio $\left(\right.$ meq L $\left.{ }^{-1}\right)$ & 2,61 \\
Magnésio $\left(\mathrm{meq} \mathrm{L}^{-1}\right)$ & 2,96 \\
Sódio (meq L $\left.{ }^{-1}\right)$ & 5,50 \\
Potássio (meq L $\left.{ }^{-1}\right)$ & 0,49 \\
Carbonatos (meq L $\left.{ }^{-1}\right)$ & 0,44 \\
Bicarbonatos (meq L-1) & 3,67 \\
Cloretos (meq L $\left.{ }^{-1}\right)$ & 4,97 \\
Sulfatos (meq L $\left.{ }^{-1}\right)$ & Presença \\
Relação de Adsorção de Sódio & 3,29 \\
(RAS) & \\
Classe de Água & $\mathrm{C}_{3} \mathrm{~S}_{1}$ \\
\hline
\end{tabular}

Fonte: Laboratório de Irrigação e Salinidade (LIS), UFCG, Campina Grande/PB, 2014.

O solo utilizado na formação do substrato foi classificado como Neossolo Flúvico, de textura franco arenosa, cujas características físicas e químicas se encontram nas (Tabelas 2 e 3).

Tabela 2. Parâmetros físicos do solo. Catolé do Rocha - PB, UEPB, 2014.

\begin{tabular}{|c|c|}
\hline ANÁLISE DE SOLO & VALORES \\
\hline $\begin{array}{l}\text { Caracteristicas Físicas } \\
\text { Granulométrica }\left(\mathrm{g} / \mathrm{kg}^{-1}\right)\end{array}$ & Profundidade $(\mathrm{cm}) 0-30$ \\
\hline Areia & 660,5 \\
\hline Silte & 181,1 \\
\hline Argila & 158,6 \\
\hline Classificação Textural & Franca Arenosa \\
\hline Densidade do solo $\left(\mathrm{g} / \mathrm{cm}^{3}\right)$ & 1,67 \\
\hline Densidade de partículas $\left(\mathrm{g} / \mathrm{cm}^{3}\right)$ & 2,65 \\
\hline Porosidade $\%$ & 36,98 \\
\hline Natural & 0,62 \\
\hline $\begin{array}{l}\text { Umidade da Capacidade de Campo a } 33,4 \mathrm{KpA}\left(\mathrm{g} / \mathrm{kg}^{-}\right. \\
\left.{ }^{1}\right)\end{array}$ & 172,2 \\
\hline $\begin{array}{l}\text { Umidade do Ponto de Murcha Permanente a } 1519,9 \\
\mathrm{KpA}\left(\mathrm{g} / \mathrm{kg}^{-1}\right)\end{array}$ & 69,8 \\
\hline Água disponível & 102,2 \\
\hline
\end{tabular}


Tabela 3. Parâmetros químicos do solo. Catolé do Rocha - PB, UEPB, 2014.

\begin{tabular}{|c|c|}
\hline ANÁLISE DE SOLO - FERTILIDADE/SALINIDADE & VALORES \\
\hline Cálcio (meq/100g de solo) & 5,09 \\
\hline Magnésio (meq/100g de solo) & 1,66 \\
\hline Sódio (meq/100g de solo) & 0,26 \\
\hline Potássio (meq/100g de solo) & 0,70 \\
\hline Soma de bases - SB - (meq/100g de solo $)$ & 7,71 \\
\hline Hidrogênio - $\left(\mathrm{cmol} / \mathrm{dm}^{3}\right)$ & 0,00 \\
\hline Alumínio - (meq/100g de solo) & 0,00 \\
\hline Capacidade de Troca de Cátions Total $-\mathrm{CTC}_{\text {total }}$ & 7,71 \\
\hline Carbonato de Cálcio Qualitativo- & Ausência \\
\hline Carbono Orgânico $-\mathrm{g} / \mathrm{Kg}^{-1}$ & 10,9 \\
\hline Matéria orgânica $-\mathrm{g} / \mathrm{Kg}^{-1}$ & 6,9 \\
\hline Nitrogênio $-g / \mathrm{Kg}^{-1}$ & 0,6 \\
\hline Fósforo assimilável- mg/ 100g & 3,27 \\
\hline $\mathrm{pH} \mathrm{H} \mathrm{H}_{2} \mathrm{O}(1: 2,5)$ & 8,20 \\
\hline Cond. Elétrica - dSm ${ }^{-1} / \mathrm{cm}$ (Suspensão Solo-Água) & 1,53 \\
\hline pH (Extrato de saturação) & 7,88 \\
\hline Cond. Elétrica - $\mathrm{dSm}^{-1} / \mathrm{cm}$ (extrato de saturação) & 0,72 \\
\hline Cloreto (meq/l) & 3,75 \\
\hline Carbonato (meq/l) & 0,00 \\
\hline Bicarbonato (meq/l) & 3,80 \\
\hline Sulfato $(\mathrm{meq} / \mathrm{l})$ & Ausência \\
\hline Cálcio (meq/l) & 2,25 \\
\hline Magnésio (meq/l) & 2,75 \\
\hline Potássio (meq/l) & 0,79 \\
\hline Sódio $(\mathrm{meq} / \mathrm{l})$ & 2,74 \\
\hline Percentagem de Adsorção de Sódio & 2,00 \\
\hline Relação de Adsorção de Sódio & 1,73 \\
\hline PSI & 3,37 \\
\hline Salinidade & Não Salino \\
\hline Classe do Solo & Normal \\
\hline
\end{tabular}

Fonte: Laboratório de Irrigação e Salinidade (LIS), UFCG, Campina Grande/PB, 2014.

O semeio foi realizado diretamente no saquinho utilizando quatro sementes distribuídas e distanciadas de forma equidistante na profundidade de $2 \mathrm{~cm}$. Aos 20 DAS realizou-se um desbaste com a finalidade de se deixar apenas as plantas mais desenvolvidas. Durante a condução do experimento, foram efetuadas capinas manuais, conforme as necessidades de manutenção da cultura no limpo.

O húmus de minhoca que foi utilizado como substrato foi feito a análise química e apresentou as seguintes características: 
Tabela 4. Atributos químicos do húmus de minhocas Vermelha da Califórnia utilizada para formação de substrato. Catolé do Rocha - PB, UEPB, 2014.

\begin{tabular}{lc}
\hline ATRIBUTOS QUÍMICOS & VALORES \\
\hline Ph $\mathrm{H}_{2} \mathrm{O}(1: 2,5)$ & 7,38 \\
Condutividade Elétrica (dS/m) & 2,11 \\
Cálcio (meq/100 g de solo) & 35,40 \\
Magnésio (meq/100 g de solo) & 19,32 \\
Sódio (meq/100 g de solo) & 1,82 \\
Potássio (meq/100 g de solo) & 1,41 \\
$\mathrm{~S}$ (meq/100 g de solo) & 57,95 \\
Hidrogênio (meq/100 g de solo) & 0,00 \\
Alumínio (meq/100 g de solo) & 0,00 \\
T (meq/100 g de solo) & 57,95 \\
Carbonato de Cálcio Qualitativo & Presente \\
Fósforo Assimilável (meq/100 g de solo) & 55,14
\end{tabular}

Laboratório de Irrigação e salinidade (LIS) do centro de Tecnologia e Recursos Naturais da Universidade Federal de campina Grande - UFCG. Catolé do Rocha - PB, UEPB, 2014.

A urina de vaca utilizada no experimento foi coletada de vacas em lactação, de rebanho leiteiro da Escola Agrotécnica do Cajueiro - EAC, município de Catolé do Rocha - PB, pertencente à Universidade Estadual da Paraíba.

Os tratamentos com urina de vaca começaram aos 15 dias após emergência (DAE), daí com intervalo de 8 dias entre as aplicações, sendo feitas 4 aplicações durante o tempo de pesquisa. Foi feita a análise química da urina de vaca e apresentou as seguintes características:

Tabela 5. Atributos químicos da urina de vaca utilizada no experimento do tamarindo. Catolé do Rocha - PB, UEPB, 2014.

\section{ESPECIFICAÇÕES}

pH

CE $\left.\left(\mathrm{dS} \mathrm{m}^{-1}\right)\right)$

NUTRIENTES

Nitrogênio (\%)

Fósforo $\left(\mathrm{mg} / \mathrm{dm}^{3}\right)$

Potássio $\left(\mathrm{cmol}_{c} \mathrm{~L}^{-1}\right)$

Cálcio $\left(\mathrm{cmol}_{\mathrm{c}} \mathrm{L}^{-1}\right)$

Magnésio $\left(\mathrm{cmol}_{\mathrm{c}} \mathrm{L}^{-1}\right)$

Sódio $\left(\mathrm{cmol}_{\mathrm{c}} \cdot \mathrm{dm}^{-3}\right)$

Enxofre $\left(\mathrm{cmol}_{\mathrm{c}} \cdot \mathrm{dm}^{-3}\right)$

${ }^{1}$ Análise realizada no Laboratório de Fertilidade do Solo do Departamento de Agronomia da Universidade Federal Rural de Pernambuco, Recife-PE; ${ }^{2}$ Análise realizada no Laboratório IBRA, Sumaré-SP; ${ }^{3}$ Valores da análise laboratorial; ${ }^{3}$ Valores transformados, em $\mathrm{g} \mathrm{L}^{-1} ;{ }^{*}$ não analisado.

Aos sessenta dias após semeio (DAS), foram analisadas a altura da planta $(\mathrm{cm})$, diâmetro do caule $(\mathrm{mm})$, comprimento da raiz $(\mathrm{cm})$, peso verde total $(\mathrm{g})$ e peso seco total $(\mathrm{g})$. 
Os dados foram analisados e interpretados a partir das análises de variância (Teste F) e pelo confronto de médias do teste de TUKEY, conforme (FERREIRA, 2007).

\section{RESULTADOS E DISCUSSÃO}

Observa-se na análise de variância descrita na tabela 1 efeitos significativos a nível de $1 \%$ de probabilidade pelo teste $\mathrm{F}$ para as combinações de substratos em todas as variáveis analisadas. Para as concentrações de urina de vaca contata-se que todas as variáveis sofreram influência significativa a nível de $1 \%$, exceto no peso seco total que foi observado efeito significativo a 5\% de probabilidade pelo teste F. Para a interação combinação de substratos $\mathrm{x}$ urina de vaca não constatou-se efeito significativo. Os coeficientes de variação oscilaram entre 2,84 e 10,35 \%, sendo considerados baixos (PIMENTEL GOMES, 2000).

Tabela 6. Resumo da análise de variância para altura de planta (AP), diâmetro de caule (DC), comprimento da raiz (CR), peso verde total (PVT) e peso seco total (PST) do tamarindo sob diferentes combinações de substratos e concentrações de urina de vaca.

\begin{tabular}{|c|c|c|c|c|c|c|}
\hline Fonte de variação & GL & & Quadrados & Médios & & \\
\hline & & AP & DC & $\mathrm{CR}$ & PVT & PST \\
\hline Combinações de substratos & 4 & $74,5 * *$ & $5,53 * *$ & $2471,7 * *$ & $25,59 * *$ & $16,49 * *$ \\
\hline Urina de vaca & 1 & $36,1 * *$ & $7,39 * *$ & $11 * *$ & $2,40 * *$ & $0,22 *$ \\
\hline Interação C x U & 4 & $10,45^{\mathrm{ns}}$ & $5,91^{\mathrm{ns}}$ & $672,2^{\mathrm{ns}}$ & $29^{\mathrm{ns}}$ & $10,30^{\mathrm{ns}}$ \\
\hline Resíduo & 30 & 0,60 & 2,64 & 44,21 & 2,61 & 1,42 \\
\hline Coeficiente de variação (\%) & & 6,85 & 10,35 & 4,23 & 3,19 & 2,84 \\
\hline
\end{tabular}

ns, **, * respectivamente não significativo, significativo a p <0,01 e p <0,05. GL: grau de liberdade.

A altura da planta e o diâmetro do caule apresentaram os melhores resultados no substrato composto por $50 \%$ de húmus de minhoca $+50 \%$ de solo $\left(\mathrm{C}_{1}\right)$ (figura $1 \mathrm{~A}$ e $\mathrm{B}$ ). Corroborando Góes et al. (2012) trabalhando com húmus de minhoca na produção de mudas de tamarindeiro observaram efeitos significativos para altura da planta e diâmetro do caule. Araújo et al. (2013) também encontrou maior diâmetro do caule ao trabalhar com substratos contento húmus de minhoca. 

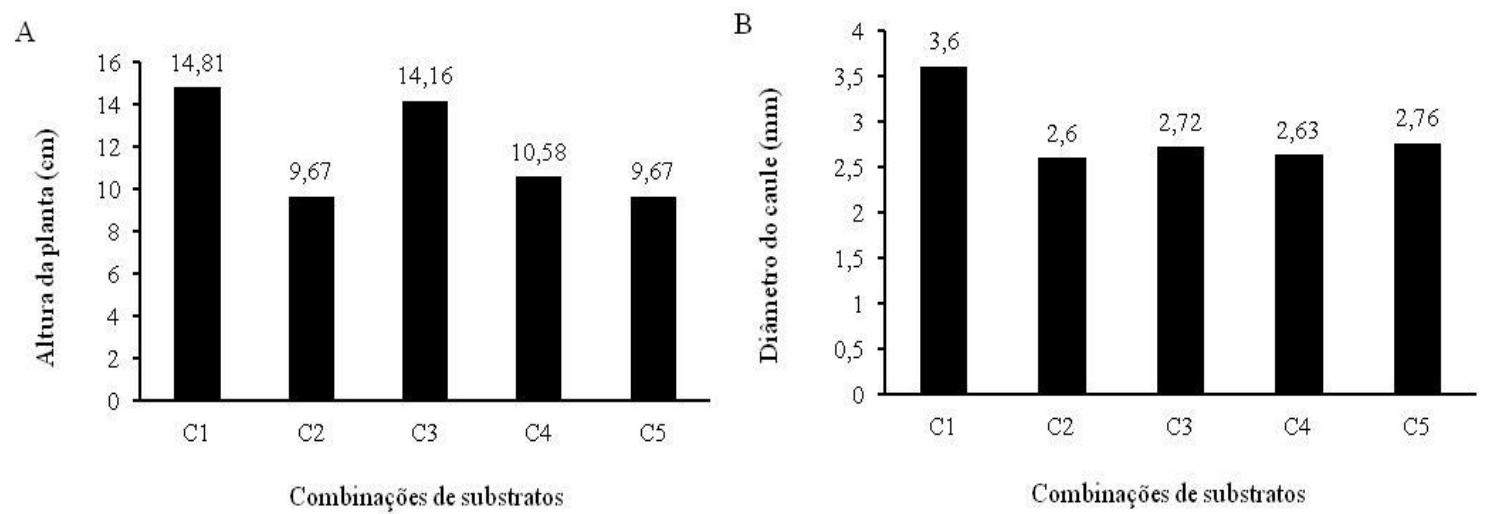

Figura 1: altura da planta (A) e diâmetro do caule (B) de tamarindo sob diferentes combinações de substratos.

Observa-se que o comprimento da raiz mostrou melhor resultado quando submetido ao substrato composto por $\mathrm{C}_{4}=33 \%$ de Pó de madeira $+33 \%$ de húmus de minhoca $+33 \%$ de solo (figura 2). Diferentemente de Góes et al. (2012) utilizando húmus de minhoca na produção de mudas de tamarindeiro não observaram efeitos significativos para o comprimento da raiz. Ensinas et al. (2011) trabalhando com mudas de rúcula sob diferentes combinações de substratos comprovaram o húmus de minhoca não obteve bons resultados quando comparado ao substrato comercial.

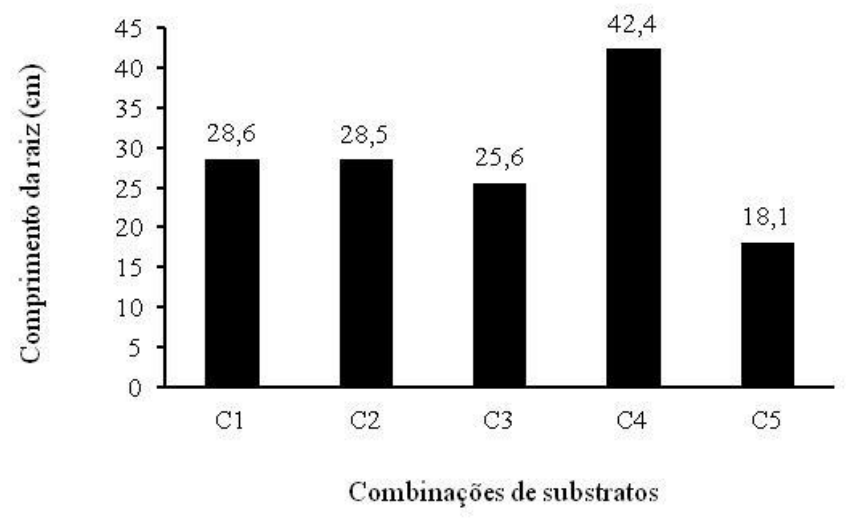

Figura 2: comprimento da raiz de tamarindo sob diferentes combinações de substratos.

Para o peso verde e seco total observou-se que o substrato $\mathrm{C}_{5}=100 \%$ solo proporcionou os melhores resultados (figura 3 A e B). Véras et al., (2014) não observaram efeitos significativos para o peso seco total estudando o efeito de substratos e fertilização orgânica em plântulas de pinheira. 

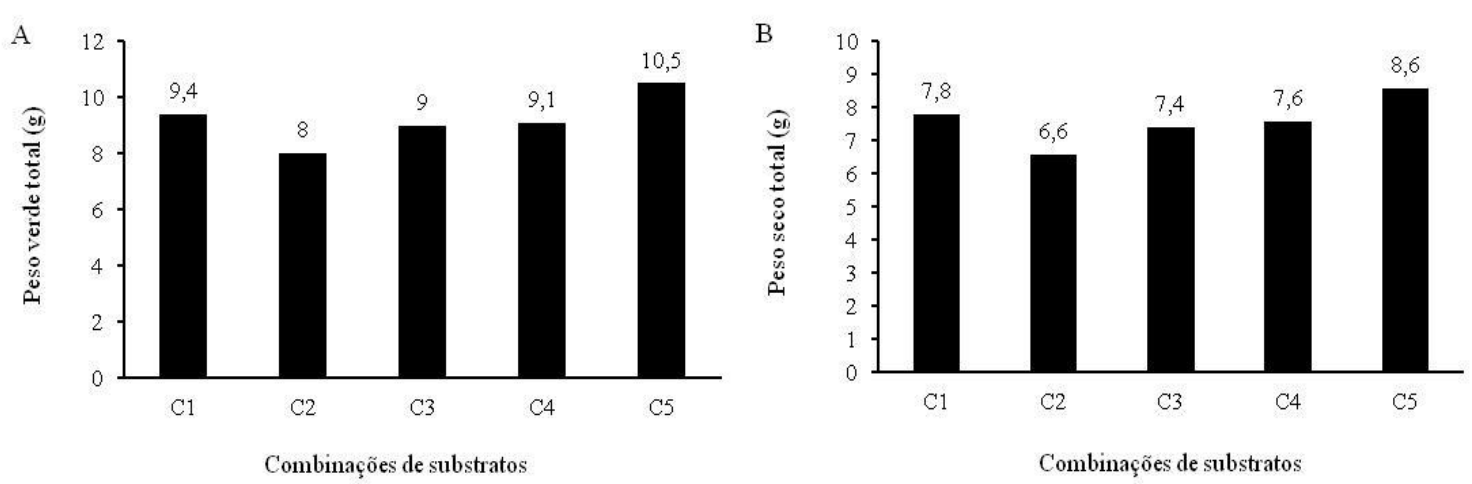

Figura 3: peso verde total (A) e peso seco total (B) de tamarindo sob diferentes combinações de substratos.

Em relação às concentrações de urina de vaca, a concentração de $1 \%$ de urina de vaca proporcionou os melhores resultados em todas as variáveis analisadas (tabela 7). Resultados diferentes foram encontrados por Silva Júnior et al., (2010) estudando a aplicação da urina de vaca no cultivo do coentro constataram que este fertilizante não proporcionou um aumento na altura da planta. Pereira et al., (2010) também não encontraram efeitos significativos estudando o efeito da urina de vaca no cultivo do alface no diâmetro do caule desta planta.

Ferreira et al., (2011) trabalhando com a cultura do girassol fertirrigado com urina de vaca e manipueira, obtiveram os melhores resultados para a variável peso seco total utilizando urina de vaca. Os resultados desse trabalho diferem dos encontrados por Véras et al (2014) trabalhando com substratos e fertilização orgânica em plântulas de pinheira, observaram que a solução a base de urina de vaca não tiveram efeitos significativos. Araújo et al (2014) estudando níveis de água disponível e doses de urina de vaca no desenvolvimento do meloeiro cantaloupe e observaram que houve influência significativa a nível de $1 \%$ para a fitomassa fresca total com a aplicação da dose $60 \mathrm{ml}$ de urina de vaca.

Araújo et al (2014) analisando o desenvolvimento inicial do maracujazeiro sob fertilização orgânica e água disponível e constataram que a aplicação de urina de vaca obtiveram os maiores resultados. Diferentemente de Véras et al., (2014) que não observaram efeitos significativos para o peso seco total estudando o efeito de substratos e fertilização orgânica em plântulas de pinheira.

Cesar et al., (2007) verificando o efeito da urina de vaca em mudas de pepino, observaram que a urina estimulou significativamente no desenvolvimento das mudas, sendo que a resposta máxima ocorreu com a concentração de $20 \%$. O efeito enraizador da urina de vaca também foi demonstrado experimentalmente quando se utilizou o produto a $50 \%$ em mudas de abacaxi (GADELHA et al., 2009). 
Os resultados encontrados neste trabalho são similares aos obtidos por Souza et al., (2010) que estudando o efeito de doses de urina de vaca no crescimento de mudas de mamoneira constataram que o diâmetro do caule foi influenciado pela aplicação de $5 \mathrm{~mL}$ de urina de vaca.

Tabela 7: Altura de plantas (AP), número de folhas (NF), diâmetro de caule (DC), comprimento da raiz (CR), peso verde total (PVT) e peso seco total (PST) do tamarindo sob diferentes concentrações de urina de vaca.

Concentrações de urina de vaca $\mathrm{U}_{1}$ $\mathrm{U}_{2}$

\begin{tabular}{ccccc} 
AP & DC & CR & PVT & PST \\
\hline $12,32 \mathrm{a}$ & $3,2 \mathrm{~b}$ & $29,2 \mathrm{~b}$ & $9,5 \mathrm{a}$ & $7,7 \mathrm{a}$ \\
$10,42 \mathrm{~b}$ & $2,4 \mathrm{a}$ & $28,1 \mathrm{a}$ & $9 \mathrm{~b}$ & $7,5 \mathrm{~b}$ \\
\hline
\end{tabular}

$\mathrm{U}_{1}=1 \%$ de urina de vaca e $\mathrm{U}_{2}=5 \%$ de urina de vaca. Médias seguidas por mesma letra nas linhas não diferem entre si pelo teste de Tukey a nível de 0,05 de probabilidade

\section{CONCLUSÕES}

As combinações de substratos $50 \%$ de húmus de minhoca $+50 \%$ de solo, $33 \%$ de pó de madeira $+33 \%$ de húmus de minhoca $+33 \%$ de solo e $100 \%$ solo tiveram os melhores resultados. Já para as concentrações de urina de vaca, foi observado um comportamento melhor na concentração de $1 \%$.

\section{REFERÊNCIAS}

ARAÚJO, D. L. de; ALVES, L. de S.; VÉRAS, M. L. M.; ANDRADE, R. Desenvolvimento inicial do maracujazeiro sob fertilização orgânica e água disponível. ACSA - Agropecuária Científica no Semi-Árido, ACSA - Agropecuária Científica no Semi-Árido, v. 10, n. 1, p. 128-133, jan - mar, 2014.

ARAÚJO, D. L. de; ALVES, L. de S.; VÉRAS, M. L. M.; ARAÚJO, D. L. de; ANDRADE, R. Níveis de água disponível e doses de urina de vaca no desenvolvimento do meloeiro cantaloupe. ACSA - Agropecuária Científica no Semi-Árido, v. 10, n. 2, p. 23-28, abr jun, 2014.

ARAÚJO, D. L. MAIA JÚNIOR, S. O. SILVA, S. F. ANDRADE, J. R. ARAÚJO, D. L. Produção de mudas de melão cantaloupe em diferentes tipos de substratos. Revista Verde, v. 8, n. 3, p. $15-20,2013$. 
CESAR, M. N. Z.; PAUlA, P. D. de; POLIDORO, J. C.; RIBEIRO, R. de L. D. \& PADOVAN, M. P. Efeito estimulante da urina de vaca sobre o crescimento de mudas de pepino, cultivadas sob manejo orgânico. Ensaios e Ciência, Campo Grande, v. 11, n. 1, p.67$71,2007$.

ENSINAS, S. C.; JUNIOR, M. T. M; ENSINAS, B. C. Desenvolvimento de mudas de rúcula em diferentes combinações de substrato. Revista Científica Eletrônica de Agronomia, Garça, v.18, n.1, p.1-7, jun, 2011.

FERREIRA, D. F. Sisvar Versão 5.0. Lavras: UFLA, 2007.

FERREIRA, E. A.; MENDONÇA, V.; SOUZA, H. A.; RAMOS, J. D. Adubação fosfatada e potássica na formação de mudas de Tamarindeiro. Scientia Agraria, Curitiba, v.9, n.4, p.475480, 2008.

FERREIRA, T. C.; SOUZA, J. T. A.; ARAUJO, E. C. L.; SILVA, K. E. da; PEREIRA, C. G.; OLIVEIRA, S. J. C. Acúmulo de fitomassa seca em girassol (Helianthus annus L.) fertirrigado com urina de vaca e manipueira. Resumos do VII Congresso Brasileiro de Agroecologia - Fortaleza/CE. Cadernos de Agroecologia, Vol 6, No. 2, Dez 2011.

GADELHA, R. S. S.; CELESTINO, R. C. A.; CARNEIRO G. M. Urina de vaca.(2009) Online. Disponível em: <http://br.geocities.com/sociedade.alternativa/urina.html>. Acesso em: 29 jan. 2015.

GÓES, G. B. de; DANTAS, D. J.; ARAÚJO, W. B. M. de; COSTA e MELO, I. G.; MENDONÇA, V. Utilização de húmus de minhoca como substrato na produção de mudas de tamarindeiro. Revista Verde (Mossoró - RN - Brasil) v.6, n.4, p.125 - 131 outubro/dezembro de 2011.

OLIVEIRA, K. S.; OLIVEIRA, K. S.; ALOUFA, M. A. I. Influência de substratos na germinação de sementes de Anadenanthera colubrina (Vell.) Brenan em condições de casa de vegetação. Revista Árvore, Viçosa, v.36, n.6, p.1073-1078, 2012.

PARENTE, H. N.; BANDEIRA, J. R.; RODRIGUES, R. C.; PARENTE, M. de O. M.; TOSTA, X. M.; SILVA JUNIOR, O. R. da. Crescimento e valor nutritivo do capim elefante submetido à adubação orgânica e mineral. Revista Brasileira de Agropecuária Sustentável, v.2, n.2, p.132-141, 2012.

PASQUAL, M.; CHALFUN, N. N. J.; RAMOS, J. D.; VALE, M. R. do; SILVA, C. R. de R. e. Fruticultura comercial: propagação de plantas frutíferas. Lavras: UFLA/FAEPE, 2001. $137 \mathrm{p}$.

PEREIRA, P. M; CARVALHO, V. N.; BASTOS, A. L.; NASCIMENTO JÚNIOR, N. A. do. Efeito da urina de vaca no cultivo da alface. CONNEPI, 1, 2010, Alagoas. Anais... Alagoas: IFAL, $2010 . \quad$ Disponível em:< http://connepi.ifal.edu.br/ocs/anais/conteudo/anais/files/conferences/1/schedConfs/1/papers/7 67/public/767-5043-1-PB.pdf > Acesso em: 15/01/2015.

PESAGRO. Urina de vaca: alternativa eficiente e barata. Niterói, 2001. 8 p. (PESAGRO. Documento, 68). 
PIMENTEL GOMES, F. Curso de estatística experimental. Piracicaba: FEALQ, p. 541, 2000.

RODRIGUES, M. L.; BATISTA, F. A.; NASCIMENTO, W. L.; VIEIRA, L. R.; RODRIGUES, R. C. Mudas de alface (Lactuca sativa L.) produzidas com diferentes substratos orgânicos. In: Congresso Norte e Nordeste de Pesquisa e Inovação, 7, Palmas, 2012. Resumos Anais... Palmas - TO, 2012.

SILVA JÚNIOR, M. B. da; SANTOS, L. N. dos ; BASTOS, A. L.; NASCIMENTO JÚNIOR, N. A. do. EFEITO DA URINA DE VACA NO CULTIVO DO COENTRO. 2010. Disponível em <http://connepi.ifal.edu.br/ocs/index.php/connepi/CONNEPI2010/paper/viewFile/767/472> Acesso em: 27/01/2015.

SOUZA, J. T. A.; FERREIRA, T. C.; FERREIRA, A. S.; OLIVEIRA, S. J. C. Comportamento de mudas de mamoneira (Ricinus communis L.) sob diferentes dosagens de urina de vaca. In: IV Congresso Brasileiro de Mamona e I Simpósio Internacional de Oleaginosas (2010 - João Pessoa). Anais... / Editores Odilon Reny R. F. da Silva e Renato Wagner da C. Rocha - Campina Grande, PB: Embrapa Algodão, 2010.

TRANI, P. E.; TERRA, M. M.; TECCIO, M. A.; TEIXEIRA, L. A. T.; HANASIRO, J. Adubação Orgânica de Hortaliças e Frutíferas. Campinas (SP) fevereiro de 2013.

VÉRAS, M. L. M.; ARAÚJO, D. L. de; ALVES, L. de S.; SILVA, T. H. da; ANDRADE, R. Efeito de substratos e fertilização orgânica em plântulas de pinheira. ACSA - Agropecuária Científica no Semi-Árido, v. 10, n. 1, p. 143-149, jan - mar, 2014.

WILLER H. Organic agriculture worldwide: the main results of the FiBL-IFOAM survey 2010. Disponível em: <http://www.ifoam.org> Acesso em: 30/01/2015. 